\title{
Environmental testing of the efficiency of IFKhAN-80, an inhibitor for corrosion protection of steel reinforcement in concrete
}

\author{
N.N. Andreev, I.A. Gedvillo, A.S. Zhmakina, D.S. Bulgakov \\ and S.S. Vesely \\ A. N. Frumkin Institute of Physical Chemistry and Electrochemistry, Russian Academy \\ of Sciences, Leninskii pr. 31, Moscow, 119071 Russian Federation \\ E-mail:n.andreev@mail.ru
}

\begin{abstract}
Environmental tests of the efficiency of IFKhAN-80, a corrosion inhibitor for steel reinforcement in concrete, have been carried out. It has been found that the electrochemical criteria for the estimation of the corrosion behavior of steel reinforcement in concrete recommended by GOST (RF State Standard) 31383-2008 are not informative under the test conditions used. In view of this, the effect of IFKhAN-80 on the kinetics of corrosion spot growth on steel surface has been analyzed. In the absence of an inhibitor, corrosion of reinforcement steel already occurs in the course of hardening of chloride-containing concrete. Once hardening is completed, the growth rate of corrosion spots decreases abruptly. The area of corroded surface remains unchanged for 6 months, then the growth of corrosion spots on the metal surface resumes. Addition of IFKhAN-80 with tempering water in amounts recommended by the developers slows down corrosion in the course of concrete hardening and during exposure under natural conditions. Application of IFKhAN80 onto the surface of concrete samples in amounts recommended by the developers can arrest the growth of corrosion spots for a long time.
\end{abstract}

Key words: corrosion inhibitors, migrating corrosion inhibitors, corrosion in concrete, reinforced concrete, IFKhAN-80.

Received: August 7, 2016. Published: September 22, 2016.

doi: $\underline{10.17675 / 2305-6894-2016-5-4-2}$

Corrosion inhibitors (both contact and migrating ones) are widely used for the protection of reinforced concrete structures [1-7]. Recently, a new corrosion inhibitor for concrete steel reinforcement was developed at the Institute of physical chemistry and electrochemistry of the Russian Academy of Sciences. It is called IFKhAN-80 and is positioned as a versatile formulation. It is a $30 \%$ aqueous solution of a non-volatile compound modified by addition of a surfactant. According to laboratory tests, IFKhAN-80 is efficient both when introduced into concrete with tempering water and when applied to a concrete surface.

The purpose of this study was to estimate the efficiency of IFKhAN-80 under natural conditions. 
At the first stage of this study, it was necessary to determine the methods for estimation of the corrosion state of reinforcement steel in concrete that would allow one to judge on the functional properties of the inhibitor. Gravimetry is usually the most informative method in tests of this kind. However, the adhesion of concrete to the pure metal is so strong that mechanical or even chemical removal of concrete traces from the steel surface results in mass losses comparable to or even exceeding the losses due to corrosion.

In view of this, we used the effect of the inhibitor on the corroded area of reinforcement steel surface as the main criterion of inhibitor efficiency. This parameter is easily determined by visual surface inspection after the test is completed and characterizes the capability of the formulation to prevent concrete delamination.

We hoped that additional information on the corrosion behavior of steel can be obtained from the results of electrochemical measurements recommended in [8]. This factor determined the shape of the concrete specimens made for the environmental tests.

\section{Experimental procedure}

The specimens for the tests ( 33 pieces) were made in the form of bars measuring $40 \times 40 \times 160$ $\mathrm{mm}$ from a chloride-containing cement-sand mixture with bars of reinforcement wire (steel St. 3 ps) totally covered with concrete. We used 2 parts of sand screened through a $2 \mathrm{~mm}$ sieve and 0.37 parts of water per 1 part of portland cement PTs 500 D0. Parts of concrete reinforcement wire with $6.5 \mathrm{~mm}$ diameter and $100 \mathrm{~mm}$ length were used. They were cleaned with emery paper and degreased with ethanol prior to concrete grouting. $\mathrm{NaCl}(3 \%$ of cement mass) was added to the specimens with tempering water.

Specimens 1-9 and 28-33 were not treated with the inhibitor at the stage of cement tempering.

IFKhAN-80 was added in the amount of $1.5 \%$ of the cement mass with respect to the dry inhibitor for specimens $10-18$, or $3 \%$ for specimens $19-27$. These dosages are recommended by the developers for application of IFKhAN-80 as a contact inhibitor.

All the samples prepared (no. 1-33) were kept for 7 days under room conditions for hardening. After that, the surface of samples $28-32$ was treated with IFKhAN-80 in the amount of $300 \mathrm{ml} / \mathrm{m}^{2}$. This dosage was recommended by the developers for application of IFKhAN-80 as a migrating inhibitor. In this case, the inhibitor mass is equivalent to the amount ( $3 \mathrm{~g}$ ) added to a sample as $1.5 \%$ inhibitor solution with tempering water.

Samples 1-3, 10-12, and 19-21 were not exposed under natural conditions but were tested at once using the procedure described below.

Samples 4-6, 13-15, 22-24, and 28-30 were exposed for 6 months (June until December) under a shed in an urban industrial atmosphere in a zone with temperate continental climate, whereas samples 7-9, 16-18, 25-27, and 31-33 were exposed under the same conditions but for 12 months (June until the next June).

Upon completion of the tests, the samples were saturated with water in a vacuum chamber and concrete was chipped away from one end of the bars in order to expose the ends of the steel reinforcement. They were connected to a potentiostat and the metal was 
polarized anodically from the steady potential by shifting the potential $(E)$ by $50 \mathrm{mV}$ every 2.5 minutes. Stainless steel plates were used as the auxiliary electrodes. The measurements were performed versus a saturated silver/silver chloride electrode. During the measurements, the current density $(i)$ at $E=+0.3 \mathrm{~V}\left(i_{\mathrm{cr}}\right)$ was measured. According to [8], it can serve as one of the criteria of the corrosion behavior of steel.

According to [8], the $i_{\text {cr }}$ values smaller than $10 \mu \mathrm{A} / \mathrm{cm}^{2}$ measured under these conditions indicate that the steel reinforcement rods are in the passive state at the time of the tests. Values of $i_{\text {cr }}$ within $10-25 \mu \mathrm{A} / \mathrm{cm}^{2}$ indicate an unstable passive state of iron, while values $i_{\mathrm{cr}}>25 \mu \mathrm{A} / \mathrm{cm}^{2}$ indicate intense corrosion.

On reaching $E=+1.0 \mathrm{~V}$, polarization was turned off. The potential of steel $\left(E_{\mathrm{cr}}\right)$ was measured $60 \pm 5$ seconds later. This value was also suggested as a criterion of the corrosion behavior of steel. According to RF State Standard 31383-2008, $E_{\text {cr }}$ values above $5 \mathrm{mV}$ indicate that steel is in passive state, while values below $5 \mathrm{mV}$ indicate intense corrosion [8].

After completion of electrochemical tests, concrete was chipped off and the steel surface was examined to estimate the corroded area $(S)$.

\section{Experimental results and discussion}

The results of tests on IFKhAN-80 efficiency depending on the preparation of samples and the time of exposure under natural conditions are presented in Table 1.

Table 1. Results of tests on IFKhAN-80 efficiency depending on the preparation of samples and time of exposure under natural conditions.

\begin{tabular}{|c|c|c|c|c|c|c|}
\hline \multirow[b]{2}{*}{ \# } & \multicolumn{2}{|c|}{$\begin{array}{l}\text { Inhibitor introduction method } \\
\text { and content }\end{array}$} & \multirow{2}{*}{$\begin{array}{l}\text { Exposu } \\
\text { re time, } \\
\text { months }\end{array}$} & \multirow{2}{*}{$\begin{array}{c}i_{\mathrm{cr}} \\
\mu \mathrm{A} / \mathrm{cm}^{2}\end{array}$} & \multirow[b]{2}{*}{$E_{\mathrm{cr}}, \mathbf{V}$} & \multirow[b]{2}{*}{$S, \%$} \\
\hline & $\begin{array}{c}\text { With } \\
\text { tempering } \\
\text { water, } \%\end{array}$ & $\begin{array}{c}\text { Surface } \\
\text { application, } \\
\mathrm{ml} / \mathrm{m}^{2}\end{array}$ & & & & \\
\hline $1-3$ & 0 & 0 & 0 & 5.85 & -0.33 & 5.9 \\
\hline $4-6$ & 0 & 0 & 6 & 2.75 & 0.14 & 5.7 \\
\hline $7-9$ & 0 & 0 & 12 & 5.46 & -0.41 & 9.9 \\
\hline $10-12$ & 1.5 & 0 & 0 & 2.53 & -0.25 & 2.3 \\
\hline $13-15$ & 1.5 & 0 & 6 & 3.83 & 0.06 & 1.9 \\
\hline $16-18$ & 1.5 & 0 & 12 & 2.09 & 0.22 & 6.6 \\
\hline $19-21$ & 3 & 0 & 0 & 0.38 & 0.31 & 0.2 \\
\hline $22-24$ & 3 & 0 & 6 & 1.12 & -0.11 & 0.2 \\
\hline $25-27$ & 3 & 0 & 12 & 1.12 & 0.24 & 2.0 \\
\hline $28-30$ & 0 & 300 & 6 & 4.95 & -0.27 & 6.2 \\
\hline $31-33$ & 0 & 300 & 12 & 4.05 & -0.1 & 6.0 \\
\hline
\end{tabular}


Steel undergoes intense corrosion in the course of hardening of chloride-containing concrete. This follows from the presence of rust spots on the reinforcement rods in samples 1-3 that were not exposed under natural conditions. The mean area of corrosion spots was $5.9 \%$ of the surface area of the reinforcement rods.

The corroded area on the metal that was not treated with the inhibitor nearly does not change in the first 6 months of sample exposure under natural conditions (compare samples 1-3 and 4-6). This may be a consequence of steel passivation. During concrete hardening, the $\mathrm{pH}$ of the pore liquid increases and apparently reaches critical values for metal passivation (at the given concentration of chlorides).

An indirect confirmation of metal passivation might be obtained from an $i_{\text {cr }}$ decrease and $E_{\mathrm{cr}}$ ennoblement. However, the data that we report below cast some doubt on the correctness of these methods for the estimation of the corrosion state of steel under the experimental conditions that we used.

A more prolonged exposure of samples (for another 6 months) under natural conditions results in a growth of the corrosion spots. For samples not treated with the inhibitor, the corroded area of reinforcement rods increases from 5.7-5.9 to $9.9 \%$ in the second 6 months of exposure under natural conditions (compare samples 1-6 and 7-9). In this case, the increase in the corroded area may be due to concrete carbonation. However, the effect of seasonal changes of the test conditions on the kinetics of corrosion propagation on the steel surface may not be ruled out, either.

Though corrosion obviously occurs, which results in the growth of corrosion spots, the measured $i_{\text {cr }}$ values for samples 7-9 were much lower than $10 \mu \mathrm{A} / \mathrm{cm}^{2}$, which is a criterion of steel passivity.

Addition of $1.5 \%$ IFKhAN-80 to concrete with tempering water strongly inhibits corrosion or at least its propagation on the steel surface in the course of concrete hardening. This follows from comparison of the areas of corrosion spots on reinforcement rods in samples $1-3$ and $10-12$.

Like in the absence of an inhibitor, the kinetics of corrosion propagation on the steel surface slows down abruptly after concrete hardening. The area of corrosion spots nearly did not change in the first 6 months of exposure under natural conditions (compare samples $10-12$ and $13-15)$.

Subsequent exposure of samples (6-12 months) resulted in a growth of corrosion spots. Their area increased by $1.2 \mathrm{~cm}^{2}$ in the second 6 months of exposure. This value is close to that obtained for non-inhibited samples $\left(1.1 \mathrm{~cm}^{2}\right)$. It is important that corrosion in this period of time was characterized by quite low $i_{\text {cr }}$ values $\left(2.1 \mu \mathrm{A} / \mathrm{cm}^{2}\right)$. Moreover, steel passivity also follows from the positive $E_{\text {cr values }}(0.2 \mathrm{~V})$, which makes the correctness of both criteria suggested in [8] doubtful.

The inhibitor in the amount of $3 \%$ introduced with tempering water essentially prevented steel corrosion during concrete hardening. Examination of samples 19-21 revealed only point-like corrosion sites covering about $0.2 \%$ of the surface area of reinforcement rods. The corroded surface area remained unchanged in the first 6 months 
(samples 22-24) and only increased to $2.0 \%$ (samples 25-28) in the second half-year of exposure. In this case, the rate of corrosion propagation on the sample surface is almost 2 times smaller than that in the absence of an inhibitor. This follows from comparison of the corroded areas on samples 4-6 and 7-9, as well as 22-24 and 25-28. It is important that samples 25-28, which are obviously subject to corrosion like in the case described above, are characterized by low $i_{\text {cr }}\left(1.12 \mu \mathrm{A} / \mathrm{cm}^{2}\right)$ and high $E_{\mathrm{cr}}$ values $(0.24 \mathrm{~V})$.

The reinforcement rods in the samples whose surfaces were treated with IFKhAN-80 apparently did not corrode throughout the entire time of exposure under natural conditions. At least, the area of corrosion spots on the steel rods in samples 28-30 and 31-33, which were exposed under natural conditions for 6 and 12 months, respectively, was equal to the surface area of steel that corroded during the hardening of samples 1-3.

Comparison of samples 13-18 and 28-33 that differed in the method of inhibitor addition but not in the inhibitor dosage allows us to make the conclusion that propagation of corrosion on the metal surface is more efficiently inhibited if IFKhAN-80 is applied on the concrete surface. This may result from partial binding of the inhibitor added with tempering water during cement hardening.

\section{Conclusions}

1. The electrochemical criteria for the estimation of the corrosion behavior of steel reinforcement in concrete recommended by GOST (RF State Standard) 31383-2008 are not informative under the test conditions. Environmental testing of the efficiency of corrosion inhibitors in concrete should be based on their effect on the kinetics of propagation of corrosion spots on the metal surface.

2. In the absence of an inhibitor, corrosion of reinforcement steel occurs as early as in the course of hardening of chloride-containing concrete. Once the hardening process is completed, the growth rate of corrosion spots decreases abruptly. The area of corroded surface remains unchanged for 6 months, then the growth of corrosion spots on the metal surface resumes.

3. Addition of IFKhAN-80 with tempering water in amounts recommended by the developers slows down corrosion in the course of concrete hardening and during prolonged exposure under natural conditions.

4. Application of IFKhAN-80 onto the surface of concrete samples in amounts recommended by the developers can arrest the growth of corrosion spots for a long time.

\section{References}

1. B. Miksic, L. Gelner, D. Bjegovic and L. Sipos, $9^{\text {th }}$ Europ. Symp. on Corrosion Inhibitors, Ferrara, 2000, vol. 1, 569.

2. J. Tritthart, Cement and Concrete Research, 2003, 33, 829.

3. N.N. Andreev, E.V. Starovoitova, I.A. Gedvillo and A.S. Zhmakina, EUROCORR-2010, Moscow, 2010, 303. 
4. E.V. Starovoitova, N.N. Andreev, I.A. Gedvillo and A.S. Zhmakina, Korroz.: mater., zashch., 2008, no. 10, 22 (in Russian).

5. N.N. Andreev, I.A. Gedvillo, A.S. Zhmakina, T.L. Zimina, V.F. Stepanova and L.P. Kharitonova, Prakt. protivokorroz. zashch., 2014, no. 1, 14 (in Russian).

6. N.N. Andreev, D.S. Bulgakov, I.A. Gedvillo, A.S. Zhmakina and S.S. Vesely, Int. J. Corros. Scale Inhib., 2014, 3,-238. doi: 10.17675/2305-6894-2014-3-4-238-245

7. F. Bolzoni, A. Brenna, G. Fumagalli, S. Goidanich, L. Lazzari, M. Ormellese and M.P. Pedeferri, Int. J. Corros. Scale Inhib., 2014, 3, 254. doi: 10.17675/2305-68942014-3-4-254-278

8. GOST 31383-2008, Protection of Concrete and Reinforced-Concrete Structures from Corrosion. Test Methods, Moscow, Standartinform, 2010 (in Russian). 